\title{
Testosterone and Blood Pressure Regulation
}

\author{
Tina Kienitz Marcus Quinkler \\ Clinical Endocrinology, Department of Internal Medicine, Gastroenterology, Hepatology and Endocrinology, \\ Charité Campus Mitte, Charité Universitätsmedizin Berlin, Berlin, Germany
}

\section{Key Words}

Testosterone $\cdot$ Androgens $\cdot$ Blood pressure $\cdot$ Hypertension $\cdot$ Sex difference

\begin{abstract}
Background: There is substantial evidence that androgens may play a role in determining sex-specific blood pressure. Men are at higher risk for developing coronary heart disease or hypertension compared to premenopausal women. However, effects of androgens on the renal and cardiovascular system are complex. This review provides a critical overview of testosterone actions. Methods: We searched Pubmed library for experimental, animal and clinical studies, using the keywords 'blood pressure', 'hypertension', 'testosterone' and 'androgens'. Results: While acute administration of testosterone seems to decrease vascular tone, the long-term net effect of androgens appears to be vasoconstriction via upregulation of thromboxane $A_{2}$ expression, norepinephrine synthesis, angiotensin II expression, and endothelin-1 action. Furthermore, androgens cause cardiac hypertrophy, promote atherosclerosis, vascular remodelling and stimulate renal prohypertensive processes involving the renin-angiotensin-aldosterone system. Androgens seem to promote oxidative stress in the kidney and may also play a role in the differentiation of brain areas involved in blood pressure regulation. Conclusion: The effects of sex steroids on different parts of the renal-vascular system are complex and often contradictory. In sum, net effects of androgen action seem to be vasoconstriction, atherosclerosis and stimulation of
\end{abstract}

the renin-angiotensin-aldosterone system. Therefore, androgens may determine blood pressure and the prevalence of cardiovascular disease.

Copyright $\odot 2008$ S. Karger AG, Basel

\section{Introduction}

Sex-Dependent Blood Pressure Regulation

Various epidemiological, clinical and experimental studies have indicated that androgens may be important determinants of sex-specific differences in arterial blood pressure. Sexual dimorphism in blood pressure develops in puberty and persists during adulthood [1-4]. Systolic blood pressure in men younger than 60 years is about 6-7 $\mathrm{mm} \mathrm{Hg}$ higher than in women, diastolic blood pressure is elevated by about 3-5 mm Hg [5]. In women older than 60 years, particularly systolic blood pressure increases. This transition takes about 5-20 years [6] until finally, hypertension becomes as prevalent in women as in men. Although the fall in estrogens after menopause may in part be responsible for this phenomenon, studies in animals suggest that the shift in the androgen/estrogen ratio after menopause and the resulting 'imbalance' might explain the transition in cardiovascular and renal function more precisely [7]. Following menopause also responsiveness to androgens might increase. Hormone replacement therapy after menopause has not been shown to significantly decrease blood pressure [8-10].

Marcus Quinkler, MD

Clinical Endocrinology, Department of Internal Medicine, Gastroenterology, Hepatology and Endocrinology, Charité Campus Mitte

Charité Universitätsmedizin Berlin, Charitéplatz 1, DE-10117 Berlin (Germany) Tel. +49 30450514 259, Fax +49 30450514 958, E-Mail marcus.quinkler@charite.de 
A number of clinical studies have indicated that androgens may affect the cardiovascular and renal system in human beings. Men have a higher risk for developing coronary artery disease and hypertension than premenopausal women [11-13]. Men with hypotestosteronemia and hyperestrogenemia have a lower incidence of coronary artery disease [14]. After orchiectomy mortality from heart disease in men decreases slightly [15]. In support, chronic anovulation and hypertestosteronemia in women, as it occurs in the polycystic ovary syndrome, is associated with hypertension [16] and an increased risk for myocardial infarction and coronary disease [15, 17-19]. Anabolic steroids (synthetic derivates of testosterone) are known to be associated with hypertension, ventricular remodelling, myocardial ischemia and sudden cardiac death [20]. However, studies on the effects of anabolic steroids have to be interpreted carefully since their use is often clandestine and few controlled studies have been performed.

In some studies, an association between lower testosterone levels in men and hypertension [21, 22], coronary artery disease $[14,23,24]$ or myocardial infarction [15] has been shown. Since circulating testosterone may decrease during stress, such as myocardial infarction, surgery, hypoxia, head trauma or psychological pressure [15], the results of these studies may reflect the response of testosterone following cardiovascular damage. A direct correlation between androgens and the renal-vascular system still needs to be shown in large clinical studies. Contradictory results in past clinical trials may be due to heterogeneous study groups regarding age and prevalence of cardiovascular disease, differences in duration of androgen treatment and the type of androgenic preparation being used.

\section{Animal Models of Sex-Dependent Blood Pressure Regulation}

Sex-specific differences in blood pressure can be observed in animals as well. Male spontaneously hypertensive rats (SHR) [25-27], Dahl salt-sensitive rats [28, 29], deoxycorticosterone acetate-salt hypertensive rats [30], and New Zealand genetically hypertensive rats [31] have higher blood pressure than females. Castration in these models decreases blood pressure [25-27, 32, 33], whereas administration of testosterone to castrated males or ovariectomized females reverses this effect $[25,26]$. Ovariectomy itself has no effect on the development of hypertension in females [26]. Also conversion from testosterone to the more potent androgen dihydrotestosterone was not found to be relevant in promoting hypertension. Administration of finasteride, which blocks this conversion, did not attenuate hypertension [27].

\section{Androgen-Modulated Cardiovascular Mechanisms}

\section{Vascular Tone}

The androgen receptor is expressed in vascular cells of rats [34] and testosterone relaxes coronary arteries in rabbits in vitro $[35,36]$ and in vivo. Short-term intracoronary testosterone administration in men with coronary artery disease causes coronary artery vasodilation and increases coronary blood flow within minutes that cannot be antagonized with androgen receptor blockers [37]. Blockers of transcription (actinomycin D) and translation (cycloheximide) do not inhibit vasodilation induced by physiological concentrations of testosterone in porcine coronary arteries [38]. Thus, the acute effects of testosterone appear to be androgen receptor independent and nongenomic. Testosterone-induced vasodilation cannot be abolished by inhibition of aromatase activity as shown in rats [39] and rabbits [36]. Administration of dihydrotestosterone, which cannot be aromatized, caused similar vasodilation in porcine coronary arteries as testosterone [40] indicating that estrogen does not contribute to testosterone-induced vasodilation.

Interestingly, testosterone-induced vasodilation is preserved in endothelial denuded vessels of various species [36, 40-42]. Testosterone, like progesterone and estradiol, mediates vasodilation of porcine coronary arteries precontracted with prostaglandin $\mathrm{F}_{2 \alpha}$ and potassium [43]. However, the mechanism behind this phenomenon is not yet fully elucidated. Testosterone and progesterone do not only seem to inhibit calcium entry via receptoroperated calcium channels and voltage-operated calcium channels $[44,45]$ like estradiol, but may regulate additional pathways such as potassium channel conductance $[36,40]$ that lead to vasorelaxation. Interestingly, testosterone does not activate nitric oxide synthesis in bovine [46] and rat endothelium [47] and inhibitors of nitric oxide synthase or guanylate cyclase did not abolish testosterone-mediated vasodilation in rat studies $[36,47,48]$.

Beneficial effects of testosterone on vascular tone have been shown in clinical case-control studies or randomized, double-blind crossover trials. Testosterone ameliorates ST segment depression in patients with angina pectoris after exercising $[15,37,49,50]$ and myocardial ischemia in patients with coronary artery disease [50,51].

Testosterone also stimulates various vasoconstricting pathways, both directly and indirectly. By increasing tyrosine hydroxylase activity in SHR, testosterone promotes norepinephrine synthesis and may hence contribute to the development of hypertension in SHR $[52,53]$. Testosterone stimulates release of the vasoconstrictor 


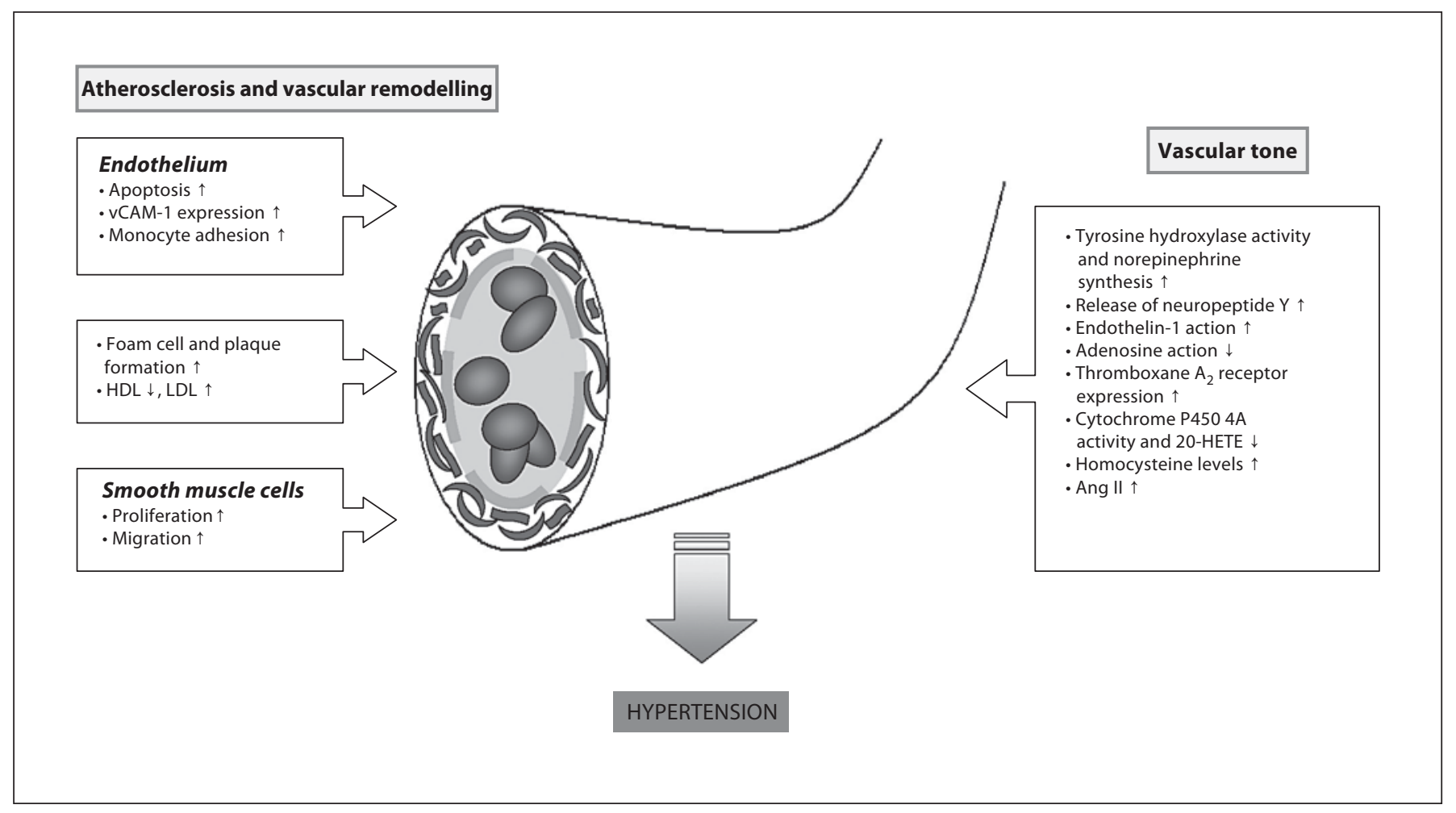

Fig. 1. Androgen effects on the vasculature. vCAM-1 = Vascular cell adhesion molecule-1.

neuropeptide $\mathrm{Y}$ in rats [54], and promotes endothelin-1 action in porcine coronary artery rings [38]. Also in patients undergoing a sex change testosterone increases endothelin-1 [55]. Testosterone is pro-vasoconstricting by inhibiting action of some vasodilating effectors such as adenosine as shown in isolated rat heart [56]. Both testosterone $[57,58]$ and its precursor androstenedione [59] increase thromboxane $\mathrm{A}_{2}$ receptor expression via an androgen receptor-dependent mechanism. This may explain the higher responsiveness of male rat aortas to thromboxane $\mathrm{A}_{2}$ compared to castrated males [58]. Testosterone increases thromboxane $\mathrm{A}_{2}$ mimetic-mediated coronary artery constriction in guinea pigs in vivo and in vitro [60]. In rats inhibition of cytochrome P450 4A, which is expressed in vascular tissues and is stimulated by androgens, reduces production of 20-hydroxyeicosatetraenoic acid (20-HETE) [61]. 20-HETE regulates vascular tone by sensitizing smooth muscle cells to vasoconstrictors and promotes myogenic, mitogenic and angiogenic actions. This suggests that 20 -HETE may be involved in androgen-induced hypertension.

In sum, testosterone seems to be able to trigger both vasodilating and vasoconstricting processes, partly de- pending on pretreatment and initial condition of the vascular cells. It may be the net effect of testosterone-mediated vasodilation and vasoconstriction that determines vascular tone and by these means regulates blood pressure. Figure 1 provides an overview of androgen effects on the vasculature.

\section{Vascular Growth and Atherogenesis}

Studies trying to elucidate testosterone's role in promoting vascular growth and atherosclerosis have revealed conflicting mechanisms: testosterone increases homocysteine levels in transsexuals [55], release of neuropeptide $\mathrm{Y}$ as shown in porcine coronary arteries [38] and synthesis of angiotensin II (Ang II) in SHR [27], known to cause vasoconstriction and induce atherosclerotic mechanisms. Testosterone also promotes mitogenic effects on rat vascular smooth muscle cells [62]. It increases expression of vascular cell adhesion molecule-1 and thus enhances adhesion of monocytes to vascular endothelium in humans [63]. In addition, it induces plaque formation in chicks [64]. Testosterone itself lowers highdensity lipoprotein and increases low-density lipoprotein levels as shown in female transsexuals [65], triggers diet- 


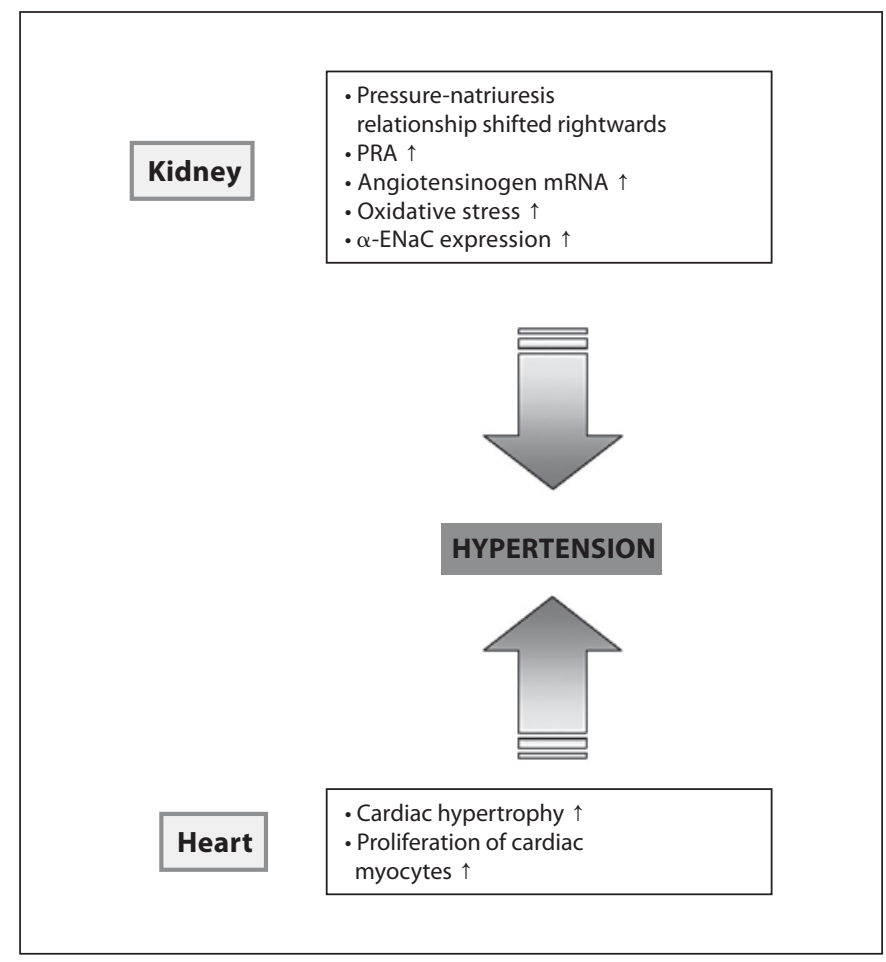

Fig. 2. Androgen effects on the heart and kidney. PRA = Plasma renin activity.

induced atherosclerosis in female monkeys and exacerbates arterial remodelling in these animals [66].

However, there are studies suggesting anti-atherosclerotic effects of testosterone. In rabbits, it inhibits post-injury-induced vascular plaque formation [35]. In cholesterol-fed rabbits, testosterone protects against development of atherosclerosis independent of lipid profiles [67]. However, it does not inhibit vascular smooth cell proliferation in rabbits in vivo [68] or migration of vascular smooth cells as shown in rats in vitro [69].

After all, it is not clear whether the anti-atherosclerotic effect is truly androgen dependent or whether it is based on a conversion of testosterone to estradiol and estradiol metabolites. Inhibition of atherosclerosis after treatment with dehydroepiandrosterone, which is a precursor of androstenedione, is reversed by the aromatase inhibitor fadrozole in rabbits [70]. However, the final mediator of the anti-atherosclerotic effect has not been identified so far.

\section{Cardiac Mechanisms}

The androgen receptor is expressed in cardiac myocytes of multiple species including humans [71]. Both tes- tosterone and dihydrotestosterone cause cardiac hypertrophy. In baroreceptor-denervated rats, testosterone induces, whereas estradiol inhibits cardiac hypertrophy [72]. Androgens stimulate growth of cardiac myocytes in vitro, suggesting that this effect is direct [71]. In contrast to testosterone, action of dihydrotestosterone in these cells is associated with an increase in atrial natriuretic peptide. Figure 2 summarizes androgen action on the heart.

\section{Androgen-Modulated Renal Mechanisms}

As discussed above testosterone may contribute to the development of atherosclerosis and damage of glomerular endothelial cells may influence renal function [55]. Men are at higher risk for developing renal injury than women [73]. The incidence of end-stage renal failure caused by glomerulonephritis and hypertensive glomerular sclerosis is higher in men than in women. Compared with females, ageing males have a decreased glomerular filtration rate and develop glomerular injury, glomerulosclerosis and proteinuria earlier than females [7, 74, 75]. Castration of rats at an early age prevents renal injury and hypertension. Transplantation of prehypertensive kidneys from SHR to Wistar-Kyoto rats results in the development of hypertension [76]. In contrast, hypertension is ameliorated in patients receiving kidney transplants from normotensive human donors [77]. Whereas transplantation of kidneys from male SHR to female SHR does not significantly increase blood pressure, transplantation of female kidneys to male SHR does not attenuate hypertension [78]. This observation suggests that hypertension in SHR does not result from an intrinsic effect of the kidney itself, but seems to be due to an extrinsic factor influencing renal function.

The androgen receptor is expressed in kidneys [27, 75] and seems to mediate the effects of testosterone on blood pressure as summarized in figure 2. Administration of the androgen receptor antagonist flutamide lowers blood pressure in male rats to the level of females or castrated males [27]. In addition, flutamide is able to attenuate saltinduced hypertension [79].

Disruption of the CYP4A14 gene (arachidonic acid $\omega-1$ hydroxylase) in mice results in an increase in renal vascular resistance and blood pressure that is severer in males than in females [80]. Castration in these animals is able to lower blood pressure, while administration of exogenous testosterone reverses this effect. 
Fig. 3. Testosterone-dependent regulation of the $\mathrm{ENaC}$ in the aldosterone-sensitive distal nephron. Sodium reabsorption via the $\mathrm{ENaC}$ is classically mediated by aldosterone (A) that binds to the mineralocorticoid receptor (MR) and activates mineralocorticoid receptor target genes, such as serum- and glucocorticoid-regulated kinase 1 (SGK1). Serum- and glucocorticoidregulated kinase 1 inactivates Nedd $4-2$ by phosphorylation and prevents Nedd4-2mediated endocytosis of the ENaC. In addition, testosterone $(\mathrm{T})$ binds to the androgen receptor (AR) and is able to upregulate expression of the $\mathrm{ENaC} \alpha$-subunit.

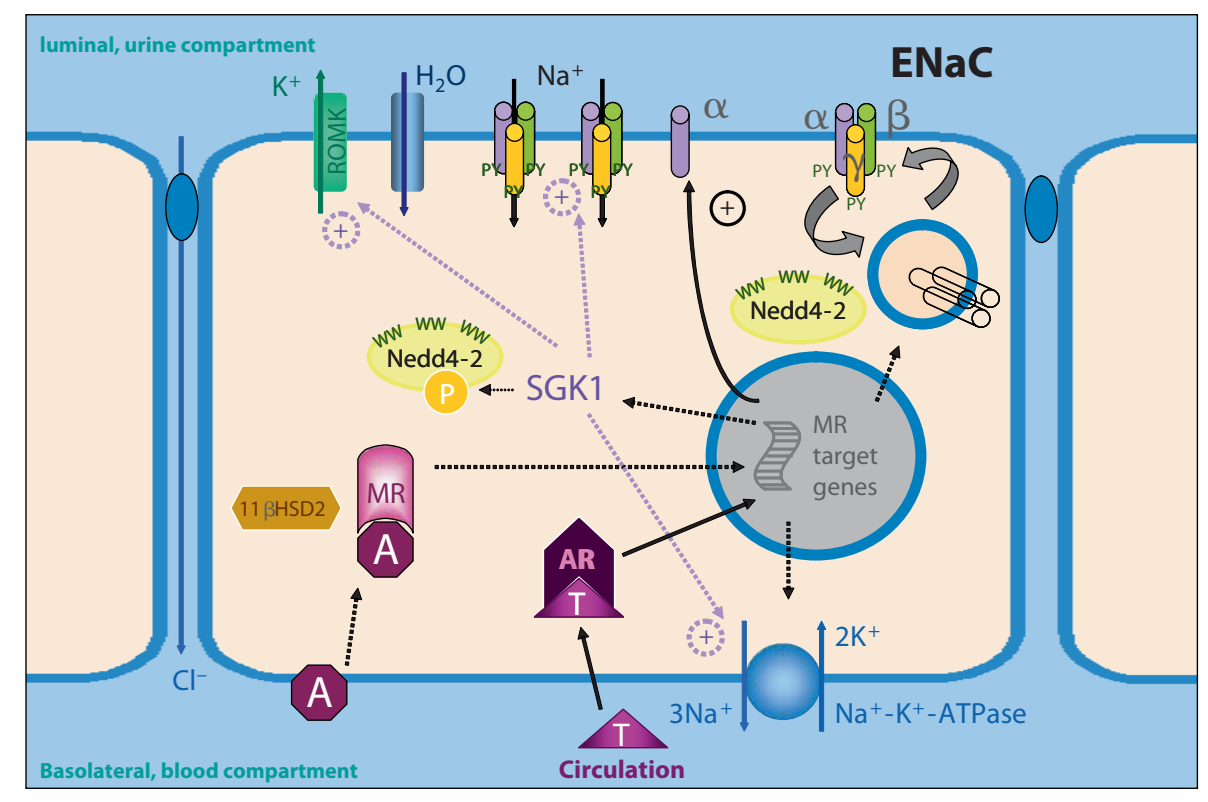

Pressure-Natriuresis Relationship and the

Renin-Angiotensin-Aldosterone System

Interestingly, the pressure-natriuresis relationship in men is shifted to the right compared to women $[7,76,81]$. At comparable renal perfusion pressures male SHR and ovariectomized SHR receiving testosterone excrete significantly less sodium and water than females, ovariectomized females or castrated males [26, 75].

Males have higher plasma renin activity than females $[7,26,75,82]$ independent of age and ethnic origin. Also plasma renin activity in postmenopausal women is higher than in premenopausal women [83]. Interestingly, plasma renin activity is lowered after castration of male SHR and increased by administration of testosterone to ovariectomized females. The increase in plasma renin activity correlates positively with the dose of testosterone given [7].

Furthermore, male rats have higher angiotensinogen mRNA levels than females. This phenomenon is regulated by androgens $[84,85]$ and stimulates the renin-angiotensin-aldosterone system (RAAS), resulting in an increased retention of sodium and water in males.

Administration of enalapril, an angiotensin-converting enzyme inhibitor, was able to reduce blood pressure in male and ovariectomized SHR receiving testosterone by $60 \%$, whereas blood pressure could be lowered only by about $40 \%$ in intact female, castrated male and ovariectomized female SHR [27]. This supports the hypothesis that androgens might in part cause hypertension via stimulation of the RAAS. An increase in Ang II has been suggested to cause oxidative stress, such as stimulation of superoxide production, quenching of nitric oxide, increase in peroxynitrite and enhanced release of vasoconstrictor $\mathrm{F}_{2}$-isoprostanes. This would decrease the renal vascular response to vasodilators, increase the response to vasoconstrictors such as Ang II and might stimulate endothelin production [7]. In addition, $\mathrm{F}_{2}$-isoprostanes have been shown to activate thromboxane receptors [86] whose expression is regulated by androgens in aortic vascular smooth muscle cells.

In how far aldosterone release is influenced by androgens has not been fully clarified yet. Some clinical studies in humans suggest sex differences in aldosterone levels that correlate with differences in blood pressure $[87,88]$. However, corticotropin-stimulated aldosterone release decreased in response to testosterone replacement in castrated male rats [89].

\section{Androgen Regulation of Proximal and Distal Renal Tubule}

In vivo microperfusion in rats revealed that androgens might directly stimulate the RAAS of the proximal tubule [90]. The exact mechanism of testosterone-induced renal injury is still unknown, but increased renal sodium reabsorption in the proximal tubule might lower pressure natriuresis and decrease sodium delivery to the macula densa [75]. This again might stimulate renin release, decrease preglomerular resistance and in combination with 
the increase in arterial pressure lead to renal injury and hypertension.

The aldosterone-sensitive distal tubule is an important control point in the regulation of renal sodium, potassium and water excretion. Interestingly, the epithelial sodium channel $(\mathrm{ENaC})$ is not only a target for aldosterone action, but seems to be regulated by testosterone as well (fig. 3). Testosterone stimulates expression of the $\mathrm{ENaC} \alpha$-subunit in human renal HKC-8 cells in vitro and in male Wistar rats in vivo [91]. By these means, androgens promote sodium and water reabsorption in the distal tubule. This mechanism might contribute in part to the sexual dimorphism in blood pressure.

\section{Influence of Androgens on Central Blood Pressure Regulation}

Female SHR that were treated with testosterone shortly after birth show a higher increase in blood pressure when exposed to testosterone in adulthood than control females [92]. Neonatal differentiation of brain areas that regulate blood pressure might therefore determine responsiveness of blood pressure to androgens in adulthood. Androgen binding sites can be found in the area postrema and in the preoptic region [93], suggested to regulate in part blood pressure and heart rate [94]. Therefore, sex-dependent differences in blood pressure might in part result from a sexually dimorphic pattern of the brain which determines central blood pressure regulation.

\section{Counterplayers: Estrogens and Progestins}

Estrogens are known to have a merely protective role regarding the cardiovascular and renal system. For example, estradiol causes acute and long-term vasodilation in human and ovine endothelium $[95,96]$, attenuates the vascular remodelling process by inhibiting vascular inflammation, neointima formation and recruitment of macrophages [97, 98], prevents mitogen-induced proliferation of cardiac fibroblasts [99] and vascular smooth muscle cells [97], and reduces glomerulosclerosis and tubular damage [100] in rats. However, studies relating estrogens with hypertension have contradictory results. Different types of estrogenic preparations seem to have specific effects as seen in multiple clinical studies [101]: while contraceptive estrogenic preparations seem to increase blood pressure, conjugated equine estrogens do not affect blood pressure. However, estradiol has a pressure-lowering effect. In hypertensive animal models, administration of estradiol resulted in a decrease in blood pressure [28, 92, 102, 103]. In contrast, ovariectomy does not prevent hypertension in SHR [27]. This suggests that the pressure-lowering effect of estradiol might not reflect a physiological process, but has to be contributed to the high doses given.

\section{Conclusions}

Androgens have diverse, even contradictory effects on the cardiovascular and renal system. In this review, we have tried to examine testosterone actions critically and outline mechanisms that may explain sex differences in blood pressure. However, findings of experimental trials are often species specific and cannot simply be applied to the human organism.

Whereas acute effects of testosterone administration may be beneficial as far as they cause vasodilation in men with coronary artery disease, long-term exposure to androgens may trigger multiple vasoconstricting mechanisms. Experimental studies have shown that androgens cause upregulation of thromboxane $\mathrm{A}_{2}$ expression, norepinephrine synthesis, Ang II expression, endothelin-1 action, release of neuropeptide $\mathrm{Y}$ and attenuation of adenosine action. Therefore, vasoconstricting pathways may outweigh vasodilating effects in the long term. There is substantial evidence that androgens promote vascular remodeling and atherosclerosis and finally increase blood pressure. Anti-atherosclerotic effects as shown in some studies might not be truly androgen dependent.

Androgens also stimulate pro-hypertensive processes through various pathways involving the RAAS and promote oxidative stress in the kidney.

Taking into account that localized enzyme systems exist in various tissues such as the kidney, heart and vasculature, autocrine or paracrine mechanisms might be involved in inhibitory or stimulating actions of androgens as well. Age-dependent metabolism of estrogens and androgens certainly influences the net effects of sex hormones on the cardiovascular and renal system. Whether androgen-induced hypertension causes renal injury or whether androgen-induced renal injury determines the development of hypertension remains to be investigated. 


\section{References}

-1 Harshfield GA, Alpert BS, Pulliam DA, et al: Ambulatory blood pressure recordings in children and adolescents. Pediatrics 1994, 94:180-184.

-2 Himmelmann A, Svensson A, Hansson L: Influence of sex on blood pressure and left ventricular mass in adolescents: the Hypertension in Pregnancy Offspring Study. J Hum Hypertens 1994;8:485-490.

- 3 Wiinberg N, Hoegholm A, Christensen HR, et al: 24-h ambulatory blood pressure in 352 normal Danish subjects, related to age and gender. Am J Hypertens 1995;8:978-986.

$\checkmark 4$ Yong LC, Kuller LH, Rutan G, et al: Longitudinal study of blood pressure: changes and determinants from adolescence to middle age. The Dormont High School follow-up study, 1957-1963 to 1989-1990. Am J Epidemiol 1993;138:973-983.

5 Stamler J, Stamler R, Riedlinger WF, et al: Hypertension screening of 1 million Americans. Community Hypertension Evaluation Clinic (CHEC) program, 1973 through 1975 JAMA 1976;235:2299-2306.

6 Burt VL, Whelton P, Roccella EJ, et al: Prevalence of hypertension in the US adult population. Results from the Third National Health and Nutrition Examination Survey, 1988-1991. Hypertension 1995;25:305-313.

7 Reckelhoff JF: Gender differences in the regulation of blood pressure. Hypertension 2001;37:1199-1208.

8 Effects of estrogen or estrogen/progestin regimens on heart disease risk factors in postmenopausal women. The Postmenopausal Estrogen/Progestin Interventions (PEPI) Trial. The Writing Group for the PEPI Trial. JAMA 1995;273:199-208.

$\checkmark 9$ Akkad AA, Halligan AW, Abrams K, et al: Differing responses in blood pressure over 24 hours in normotensive women receiving oral or transdermal estrogen replacement therapy. Obstet Gynecol 1997;89:97-103.

-10 Pripp U, Hall G, Csemiczky G, et al: A randomized trial on effects of hormone therapy on ambulatory blood pressure and lipoprotein levels in women with coronary artery disease. J Hypertens 1999;17:1379-1386.

11 Anastos K, Charney P, Charon RA, et al: Hypertension in women: what is really known? The Women's Caucus, Working Group on Women's Health of the Society of General Internal Medicine. Ann Intern Med 1991;115: 287-293.

-12 Khaw KT, Barrett-Connor E: Blood pressure and endogenous testosterone in men: an inverse relationship. J Hypertens 1988;6:329332.

-13 Messerli FH, Garavaglia GE, Schmieder RE, et al: Disparate cardiovascular findings in men and women with essential hypertension. Ann Intern Med 1987;107:158-161.
14 Phillips GB, Pinkernell BH, Jing TY: The association of hypotestosteronemia with coronary artery disease in men. Arterioscler Thromb 1994;14:701-706.

15 Kalin MF, Zumoff B: Sex hormones and coronary disease: a review of the clinical studies. Steroids 1990;55:330-352.

16 Chen MJ, Yang WS, Yang JH, et al: Relationship between androgen levels and blood pressure in young women with polycystic ovary syndrome. Hypertension 2007;49: 1442-1447.

17 Mattsson LA, Cullberg G, Hamberger L, et al: Lipid metabolism in women with polycystic ovary syndrome: possible implications for an increased risk of coronary heart disease. Fertil Steril 1984;42:579-584.

18 Soranno D, Prasad V, David R, et al: Hypertension and virilization caused by a unique desoxycorticosterone- and androgen-secreting adrenal adenoma. J Pediatr Endocrinol Metab 1999;12:215-220.

19 Talbott E, Guzick D, Clerici A, et al: Coronary heart disease risk factors in women with polycystic ovary syndrome. Arterioscler Thromb Vasc Biol 1995;15:821-826.

20 Sullivan ML, Martinez CM, Gennis P, et al: The cardiac toxicity of anabolic steroids. Prog Cardiovasc Dis 1998;41:1-15.

21 Hughes GS, Mathur RS, Margolius HS: Sex steroid hormones are altered in essential hypertension. J Hypertens 1989;7:181-187.

22 Phillips GB, Jing TY, Resnick LM, et al: Sex hormones and hemostatic risk factors for coronary heart disease in men with hypertension. J Hypertens 1993;11:699-702.

23 English KM, Mandour O, Steeds RP, et al: Men with coronary artery disease have lower levels of androgens than men with normal coronary angiograms. Eur Heart J 2000;21: 890-894.

24 English KM, Steeds R, Jones TH, et al: Testosterone and coronary heart disease: is there a link? QJM 1997;90:787-791.

25 Chen YF, Meng QC: Sexual dimorphism of blood pressure in spontaneously hypertensive rats is androgen dependent. Life Sci 1991;48:85-96.

26 Reckelhoff JF, Zhang H, Granger JP: Testosterone exacerbates hypertension and reduces pressure-natriuresis in male spontaneously hypertensive rats. Hypertension 1998;31: 435-439.

27 Reckelhoff JF, Zhang H, Srivastava K: Gender differences in development of hypertension in spontaneously hypertensive rats: role of the renin-angiotensin system. Hypertension 2000;35:480-483.

28 Crofton JT, Share L: Gonadal hormones modulate deoxycorticosterone-salt hypertension in male and female rats. Hypertension 1997;29:494-499.
29 Rowland NE, Fregly MJ: Role of gonadal hor mones in hypertension in the Dahl salt-sensitive rat. Clin Exp Hypertens A 1992;14: 367-375.

30 Ouchi Y, Share L, Crofton JT, et al: Sex difference in the development of deoxycorticosterone-salt hypertension in the rat. Hypertension 1987;9:172-177.

31 Ashton N, Balment RJ: Sexual dimorphism in renal function and hormonal status of New Zealand genetically hypertensive rats. Acta Endocrinol (Copenh) 1991;124:91-97.

32 Ganten U, Schroder G, Witt M, et al: Sexual dimorphism of blood pressure in spontaneously hypertensive rats: effects of anti-androgen treatment. J Hypertens 1989;7:721726.

33 Iams SG, Wexler BC: Retardation in the development of spontaneous hypertension in $\mathrm{SH}$ rats by gonadectomy. J Lab Clin Med 1977;90:997-1003.

34 Oparil S, Levine RL, Chen SJ, et al: Sexually dimorphic response of the balloon-injured rat carotid artery to hormone treatment. Circulation 1997;95:1301-1307.

35 Hanke H, Lenz C, Hess B, et al: Effect of testosterone on plaque development and androgen receptor expression in the arterial vessel wall. Circulation 2001;103:1382-1385.

36 Yue P, Chatterjee K, Beale C, et al: Testosterone relaxes rabbit coronary arteries and aorta. Circulation 1995;91:1154-1160.

37 Webb CM, McNeill JG, Hayward CS, et al: Effects of testosterone on coronary vasomotor regulation in men with coronary heart disease. Circulation 1999;100:1690-1696.

38 Teoh H, Quan A, Leung SW, et al: Differential effects of 17beta-estradiol and testosterone on the contractile responses of porcine coronary arteries. Br J Pharmacol 2000;129: 1301-1308.

39 Tep-areenan P, Kendall DA, Randall MD: Testosterone-induced vasorelaxation in the rat mesenteric arterial bed is mediated predominantly via potassium channels. $\mathrm{Br} \mathrm{J}$ Pharmacol 2002;135:735-740.

40 Deenadayalu VP, White RE, Stallone JN, et al: Testosterone relaxes coronary arteries by opening the large-conductance, calcium-activated potassium channel. Am J Physiol Heart Circ Physiol 2001;281:H1720-H1727.

41 Crews JK, Khalil RA: Gender-specific inhibition of $\mathrm{Ca}^{2+}$ entry mechanisms of arterial vasoconstriction by sex hormones. Clin Exp Pharmacol Physiol 1999;26:707-715.

42 Murphy JG, Khalil RA: Decreased $\left[\mathrm{Ca}^{2+}\right]_{\mathrm{i}}$ during inhibition of coronary smooth muscle contraction by 17beta-estradiol, progesterone, and testosterone. J Pharmacol Exp Ther 1999;291:44-52.

43 Crews JK, Khalil RA: Antagonistic effects of 17beta-estradiol, progesterone, and testosterone on $\mathrm{Ca}^{2+}$ entry mechanisms of coronary vasoconstriction. Arterioscler Thromb Vasc Biol 1999;19:1034-1040. 
-44 Jones RD, Hugh Jones T, Channer KS: The influence of testosterone upon vascular reactivity. Eur J Endocrinol 2004;151:29-37.

45 Jones RD, Pugh PJ, Jones TH, et al: The vasodilatory action of testosterone: a potassium-channel opening or a calcium antagonistic action? Br J Pharmacol 2003;138: 733-744.

46 Goetz RM, Thatte HS, Prabhakar P, et al: Estradiol induces the calcium-dependent translocation of endothelial nitric oxide synthase. Proc Natl Acad Sci USA 1999;96: 2788-2793.

-47 Honda H, Unemoto T, Kogo H: Different mechanisms for testosterone-induced relaxation of aorta between normotensive and spontaneously hypertensive rats. Hypertension 1999;34:1232-1236.

48 Jones RD, English KM, Pugh PJ, et al: Pulmonary vasodilatory action of testosterone: evidence of a calcium antagonistic action. J Cardiovasc Pharmacol 2002;39:814-823.

-49 Jaffe MD: Effect of testosterone cypionate on postexercise ST segment depression. $\mathrm{Br}$ Heart J 1977;39:1217-1222.

50 Rosano GM, Leonardo F, Pagnotta P, et al: Acute anti-ischemic effect of testosterone in men with coronary artery disease. Circulation 1999;99:1666-1670.

51 Webb CM, Adamson DL, de Zeigler D, et al: Effect of acute testosterone on myocardial ischemia in men with coronary artery disease. Am J Cardiol 1999;83:437-439, A9.

52 Kumai T, Tanaka M, Watanabe M, et al: Elevated tyrosine hydroxylase mRNA levels in the adrenal medulla of spontaneously hypertensive rats. Jpn J Pharmacol 1994;65:367369.

-53 Kumai T, Tanaka M, Watanabe M, et al: Influence of androgen on tyrosine hydroxylase mRNA in adrenal medulla of spontaneously hypertensive rats. Hypertension 1995;26: 208-212.

54 Zukowska-Grojec Z: Neuropeptide Y. A novel sympathetic stress hormone and more. Ann NY Acad Sci 1995;771:219-233.

55 Giltay EJ, Hoogeveen EK, Elbers JM, et al: Effects of sex steroids on plasma total homocysteine levels: a study in transsexual males and females. J Clin Endocrinol Metab 1998; 83:550-553.

56 Ceballos G, Figueroa L, Rubio I, et al: Acute and nongenomic effects of testosterone on isolated and perfused rat heart. J Cardiovasc Pharmacol 1999;33:691-697.

-57 Masuda A, Mathur R, Halushka PV: Testosterone increases thromboxane $A_{2}$ receptors in cultured rat aortic smooth muscle cells. Circ Res 1991;69:638-643.

58 Matsuda K, Ruff A, Morinelli TA, et al: Testosterone increases thromboxane $\mathrm{A}_{2}$ receptor density and responsiveness in rat aortas and platelets. Am J Physiol 1994;267:H887H893.
Zucker TP, Higashiura K, Mathur RS, et al: Androstenedione increases thromboxane $\mathrm{A}_{2}$ receptors in human erythroleukemia cells. Life Sci 1996;58:683-690.

60 Schror K, Morinelli TA, Masuda A, et al: Testosterone treatment enhances thromboxane $\mathrm{A}_{2}$ mimetic induced coronary artery vasoconstriction in guinea pigs. Eur J Clin Invest 1994;24(suppl 1):50-52.

61 Singh H, Cheng J, Deng H, et al: Vascular cytochrome P450 4A expression and 20-hydroxyeicosatetraenoic acid synthesis contribute to endothelial dysfunction in androgen-induced hypertension. Hypertension 2007;50:123-129.

62 Fujimoto R, Morimoto I, Morita E, et al: Androgen receptors, 5 alpha-reductase activity and androgen-dependent proliferation of vascular smooth muscle cells. J Steroid Biochem Mol Biol 1994;50:169-174.

63 McCrohon JA, Jessup W, Handelsman DJ, et al: Androgen exposure increases human monocyte adhesion to vascular endothelium and endothelial cell expression of vascular cell adhesion molecule-1. Circulation 1999; 99:2317-2322.

64 Toda T, Toda Y, Cho BH, et al: Ultrastructural changes in the comb and aorta of chicks fed excess testosterone. Atherosclerosis 1984;51:47-57.

65 Goh HH, Loke DF, Ratnam SS: The impact of long-term testosterone replacement therapy on lipid and lipoprotein profiles in women. Maturitas 1995;21:65-70.

66 Adams MR, Williams JK, Kaplan JR: Effects of androgens on coronary artery atherosclerosis and atherosclerosis-related impairment of vascular responsiveness. Arterioscler Thromb Vasc Biol 1995;15:562-570.

67 Alexandersen P, Haarbo J, Byrjalsen I, et al: Natural androgens inhibit male atherosclerosis: a study in castrated, cholesterol-fed rabbits. Circ Res 1999;84:813-819.

68 Bruck B, Brehme U, Gugel N, et al: Genderspecific differences in the effects of testosterone and estrogen on the development of atherosclerosis in rabbits. Arterioscler Thromb Vasc Biol 1997; 17:2192-2199.

69 Kolodgie FD, Jacob A, Wilson PS, et al: Estradiol attenuates directed migration of vascular smooth muscle cells in vitro. Am J Pathol 1996;148:969-976.

70 Hayashi T, Esaki T, Muto E, et al: Dehydroepiandrosterone retards atherosclerosis formation through its conversion to estrogen: the possible role of nitric oxide. Arterioscler Thromb Vasc Biol 2000;20:782-792.

71 Marsh JD, Lehmann MH, Ritchie RH, et al: Androgen receptors mediate hypertrophy in cardiac myocytes. Circulation 1998;98:256261.

72 Cabral AM, Vasquez EC, Moyses MR, et al: Sex hormone modulation of ventricular hypertrophy in sinoaortic denervated rats. Hypertension 1988;11:193-I97.
3 Silbiger SR, Neugarten J: The impact of gender on the progression of chronic renal disease. Am J Kidney Dis 1995;25:515-533.

74 Baylis C: Age-dependent glomerular damage in the rat. Dissociation between glomerular injury and both glomerular hypertension and hypertrophy. Male gender as a primary risk factor. J Clin Invest 1994;94: 1823-1829.

75 Reckelhoff JF, Granger JP: Role of androgens in mediating hypertension and renal injury. Clin Exp Pharmacol Physiol 1999;26:127131.

76 Hall JE, Mizelle HL, Hildebrandt DA, et al: Abnormal pressure natriuresis. A cause or a consequence of hypertension? Hypertension 1990;15:547-559.

77 Curtis JJ, Luke RG, Dustan HP, et al: Remission of essential hypertension after renal transplantation. N Engl J Med 1983;309: 1009-1015.

78 Harrap SB, Wang BZ, MacLellan DG: Renal transplantation between male and female spontaneously hypertensive rats. Hypertension 1992;19:431-434.

79 Caplea A, Seachrist D, Dunphy G, et al: Sodium-induced rise in blood pressure is suppressed by androgen receptor blockade. Am J Physiol Heart Circ Physiol 2001;280: H1793-H1801.

80 Holla VR, Adas F, Imig JD, et al: Alterations in the regulation of androgen-sensitive Cyp 4a monooxygenases cause hypertension. Proc Natl Acad Sci USA 2001;98:5211-5216.

81 Guyton AC, Coleman TG, Cowley AV Jr, et al: Arterial pressure regulation. Overriding dominance of the kidneys in long-term regulation and in hypertension. Am J Med 1972; 52:584-594.

82 James GD, Sealey JE, Muller F, et al: Renin relationship to sex, race and age in a normotensive population. J Hypertens Suppl 1986; 4:S387-S389.

83 Schunkert H, Danser AH, Hense HW, et al: Effects of estrogen replacement therapy on the renin-angiotensin system in postmenopausal women. Circulation 1997;95:39-45.

84 Chen YF, Naftilan AJ, Oparil S: Androgendependent angiotensinogen and renin messenger RNA expression in hypertensive rats. Hypertension 1992;19:456-463.

$>85$ Ellison KE, Ingelfinger JR, Pivor M, et al: Androgen regulation of rat renal angiotensinogen messenger RNA expression. J Clin Invest 1989;83:1941-1945.

86 Morrow JD, Roberts LJ: The isoprostanes: unique bioactive products of lipid peroxidation. Prog Lipid Res 1997;36:1-21.

87 Miller JA, Anacta LA, Cattran DC: Impact of gender on the renal response to angiotensin II. Kidney Int 1999;55:278-285.

88 Schunkert H, Hense HW, Andus T, et al: Relation between dehydroepiandrosterone sulfate and blood pressure levels in a population-based sample. Am J Hypertens 1999;12: 1140-1143. 
89 Kau MM, Lo MJ, Wang SW, et al: Inhibition of aldosterone production by testosterone in male rats. Metabolism 1999;48:1108-1114.

90 Quan A, Chakravarty S, Chen JK, et al: Androgens augment proximal tubule transport. Am J Physiol Renal Physiol 2004;287:F452F459.

-91 Quinkler M, Bujalska IJ, Kaur K, et al: Androgen receptor-mediated regulation of the alpha-subunit of the epithelial sodium channel in human kidney. Hypertension 2005;46 787-798.

-92 Cambotti LJ, Cole FE, Gerall AA, et al: Neonatal gonadal hormones and blood pressure in the spontaneously hypertensive rat. Am J Physiol 1984;247:E258-E264.

93 Bachmann J, Feldmer M, Ganten U, et al: Sexual dimorphism of blood pressure: possible role of the renin-angiotensin system. J Steroid Biochem Mol Biol 1991;40:511-515.
94 Skoog KM, Mangiapane ML: Area postrema and cardiovascular regulation in rats. Am J Physiol 1988;254:H963-H969.

95 Caulin-Glaser T, Garcia-Cardena G, Sarrel $\mathrm{P}$, et al: 17Beta-estradiol regulation of human endothelial cell basal nitric oxide release, independent of cytosolic $\mathrm{Ca}^{2+}$ mobilization. Circ Res 1997;81:885-892.

96 Chen Z, Yuhanna IS, Galcheva-Gargova Z, et al: Estrogen receptor alpha mediates the nongenomic activation of endothelial nitric oxide synthase by estrogen. J Clin Invest 1999;103:401-406.

97 Dubey RK, Jackson EK: Estrogen-induced cardiorenal protection: potential cellular, biochemical, and molecular mechanisms. Am J Physiol Renal Physiol 2001;280:F365F388.

98 Mendelsohn ME, Karas RH: The protective effects of estrogen on the cardiovascular system. N Engl J Med 1999;340:1801-1811.
-99 Dubey RK, Gillespie DG, Jackson EK, et al: 17Beta-estradiol, its metabolites, and progesterone inhibit cardiac fibroblast growth. Hypertension 1998;31:522-528.

100 Mulroney SE, Woda C, Johnson M, et al: Gender differences in renal growth and function after uninephrectomy in adult rats. Kidney Int 1999;56:944-953.

101 Dubey RK, Oparil S, Imthurn B, et al: Sex hormones and hypertension. Cardiovasc Res 2002;53:688-708.

102 Sasaki T, Ohno Y, Otsuka K, et al: Oestrogen attenuates the increases in blood pressure and platelet aggregation in ovariectomized and salt-loaded Dahl salt-sensitive rats. J Hypertens 2000;18:911-917.

103 Sharkey LC, Holycross BJ, Park S, et al: Effect of ovariectomy and estrogen replacement on cardiovascular disease in heart failure-prone SHHF/Mcc-facp rats. J Mol Cell Cardiol 1999;31:1527-1537. 